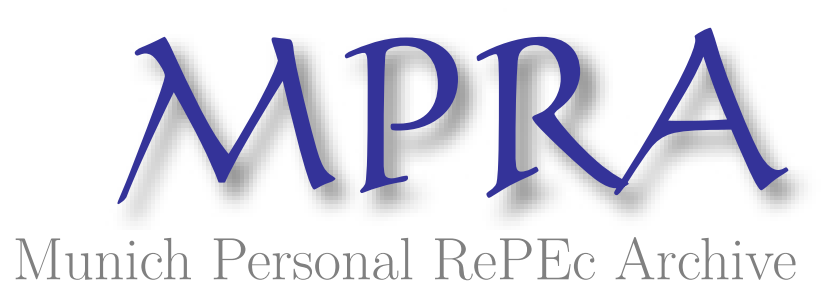

\title{
Economic and Financial Crises and the Predictability of U.S. Stock Returns
}

Hartmann, Daniel and Kempa, Bernd and Pierdzioch, Christian

October 2006

Online at https://mpra.ub.uni-muenchen.de/2920/

MPRA Paper No. 2920, posted 25 Apr 2007 UTC 


\title{
Economic and Financial Crises and the Predictability of U.S. Stock Returns
}

Daniel Hartmann, Bernd Kempa, and Christian Pierdzioch

\begin{abstract}
We argue that the use of publicly available and easily accessible information on economic and financial crises to detect structural breaks in the link between stock returns and macroeconomic predictor variables improves the performance of simple trading rules in real time. In particular, our results suggest that accounting for structural breaks and regime shifts in forecasting regressions caused by economic and financial crises has the potential to increase the out-of-sample predictability of stock returns, the performance of simple trading rules, and the market-timing ability of an investor trading in the U.S. stock market.
\end{abstract}

Keywords: Forecasting stock returns, financial and economic crises, trading rules

JEL classification: C53, E44, G11

\section{Addresses:}

Daniel Hartmann

Saarland University

Department of Economics

E-mail: da.hartmann@mx.uni-saarland.de

Bernd Kempa

European University Viadrina Frankfurt/Oder

Department of Economics

E-mail: kempa@euv-frankfurt-o.de

Christian Pierdzioch

Saarland University

(corresponding author)

Department of Economics

E-mail: c.pierdzioch@mx.uni-saarland.de

P.O.B. 151150

66041 Saarbruecken

Germany

Phone: +49-681-302-58195

Fax: +49-681-302-58193 


\section{Introduction}

A growing body of literature centers around the question of whether macroeconomic variables contain information that is useful for forecasting stock returns (Fama and French 1989, Chen et al. 1986, Pesaran and Timmermann 1995, Rapach et al. 2005, to name just a few). For a long time, the literature has not paid much attention to the fact that forecasting regressions linking stock returns to macroeconomic variables may be subject to structural breaks. Recently, however, evidence of structural breaks has been provided by, among others, Timmermann (2001), Rapach and Wohar (2006), and Paye and Timmermann (2006). This evidence has led researchers to explore the implications of structural breaks and regime changes for forecasting stock returns and tactical asset allocation (Perez-Quiros and Timmermann 2000, Ang and Bekeart 2002, Pesaran and Timmermann 2002).

Structural breaks in forecasting regressions have the potential to negatively affect the quality of forecasts of stock returns, and they may have a significant adverse effect on the market-timing ability of an investor. In order to improve the out-of-sample forecasts of stock returns, an investor therefore needs timely real-time information on structural breaks in forecasting regressions. Statistical tests for structural breaks are numerous, and given the mounting evidence of structural breaks in economic and financial time series many new tests have been developed (Andrews and Ploberger 1994; Bai and Perron 1998). Even statistical tests that may guide an investor to detect structural breaks in forecasting regressions in real time are now available (Pesaran and Timmermann 2002).

The new statistical tests for structural breaks have the potential to improve the performance of investment decisions in future. However, they may be of limited value in analyzing investor behavior and stock return dynamics in historical time series for at least two reasons. First, such tests have been developed only recently and have not been available long enough to allow an investor to utilize these new techniques in real time to search for structural breaks and refine forecasting regressions for stock returns. Second, the identification of structural breaks is a purely statistical exercise mostly unrelated to predictable or observable economic events. For both of 
these reasons, one should account for an investor's limited historical information set when empirically studying investor behavior and stock return dynamics.

Beside the question of whether an investor, in real time, would have been able to predict stock returns using macroeconomic variables as predictor variables, natural follow-up questions are whether such an investor would have been able to use out-of-sample forecasts of stock returns to improve the performance of simple trading rules and for market-timing purposes. Last but not least, researchers are interested in what can be learned from these studies about market efficiency. To obtain valid answers to these questions, it is important to track as closely as possible the information set of a real-time investor, and to account for the fact that this information set did not contain information on the recent vintage of statistical tests for structural breaks.

We argue in this paper that an investor, in real time, could have used publicly available and easily accessible information on economic and financial crises to detect structural breaks in the link between stock returns and macroeconomic predictor variables, and thereby improve the performance of simple trading rules. Our approach contributes to the ongoing research on the implications of regime changes, extreme events, and systemic financial crises and market crashes for an investor's optimal portfolio choice (Ang and Bekeart 2002, Lui et al. 2003, Das and Uppal 2004, Kole et al. 2006). In order to illustrate our argument, we extend the recursive modeling approach developed by Pesaran and Timmermann $(1995,2000)$ such that it can be used to account for potential structural breaks in the links between stock returns and macroeconomic predictor variables. The recursive modeling approach is tailored to account for the fact that an investor, in real time, must forecast stock returns under conditions of model uncertainty. The recursive modeling approach stipulates that an investor solves this decision problem by systematically searching over a large number of different forecasting models to identify the optimal forecasting model. As new information on stock returns and macroeconomic predictor variables becomes available, an investor recursively restarts this search process and updates the optimal forecasting model.

We show that an investor could have easily conditioned this search-and-updating process on information on economic and financial crises using an easy-to-measure and timely crisis indicator. 
Based on monthly data for the U.S. stock market for the period 1973-2006, we use the default spread as our indicator of economic and financial crises. The default spread is defined as the difference between the yields on BAA and AAA rated corporate bond portfolios. Fama and French (1989) have analyzed the link between expected excess stock returns and the default premium, De Bondt (2005) has reported that the default spread leads the stock market, and Elton et al. (2001) have documented that the default spread can be explained as a reward for bearing systemic risk. Therefore, the default spread appears to be an appropriate measure of economic and financial crises. Not surprisingly, the default spread markedly increased in times of economic and financial crises like the oil price shocks of the 1970s, the Latin American debt crises of the early 1980s, the U.S. Savings and Loans debacle of the mid-1980s, and the events surrounding the 9/11 terror attacks and the subsequent accounting scandals. We argue that an investor who would have used the default spread as an easy-to-measure and timely real-time indicator of crisis-induced structural breaks and regime changes could have significantly improved the out-of-sample forecasts of stock returns, the performance of simple trading rules, and the market-timing ability.

Of course, our suggestion of basing inference regarding structural breaks solely on the default spread does not optimally account for structural breaks and regime shifts in forecasting regressions in a statistical sense. Moreover, our approach is also unlikely to be optimal in an economic sense, as investor's wealth is not necessarily maximized. However, our rule provides a useful rule-ofthumb to derive out-of-sample forecasts of stock returns from a limited set of information. This set of real-time information does not depend on the exact timing and magnitude of structural breaks. Rather, given that there is large uncertainty in real time about the exact timing and magnitude of structural breaks, we consider an investor who makes use of a pragmatic modeling approach to account for potential structural breaks and regime shifts in forecasting regressions. This pragmatic approach only requires an investor to collect publicly available information on the default spread, and to condition out-of-sample forecasts of stock returns on this easy-to-measure indicator of economic and financial crises. We show that implementing this pragmatic approach reveals new insights on the well-documented evidence of predictability of stock returns. 
Our results also add a new facet to the large literature on cyclical variations in stock returns. For example, Whitelaw (1997) has found that conditional Sharpe ratios tend to be lower around peaks of the economy, but very high around troughs. Perez-Quiros and Timmermann (2000) have reported that the expected stock returns of small firms tend to display a larger sensitivity with respect to credit market conditions compared to the stock returns of large firms with ample collateral. Their results are consistent with theories of imperfect capital markets that predict cyclical variations in credit market conditions over the business cycle. Cooper et al. (2001) have shown that business-cycle-related predictor variables can be used to develop profitable trading strategies that invest in size and book-to-market decile portfolios. Using the NBER recession indicator to classify the phases of the business cycle, they show that their results are likely to reflect time variation in aggregate, macroeconomic, nondiversifiable risk. Our results contribute to this literature in that we analyze how the links between stock returns and macroeconomic predictor variables vary across regimes of economic and financial crises. We show that the variation we detect does not merely reflect changes in the stance of the business cycle.

In Section 2, we describe our data. We also describe how we use the default spread to identify economic and financial crises. Furthermore, we report results of tests for structural breaks, and we present the results of estimating a threshold model. The threshold model gives a clue as to which threshold of the default spread may be the most useful to identify economic and financial crises. In Section 3, we describe the recursive modeling approach we used to study the variation of the links between stock returns and macroeconomic predictor variables across economic and financial crises. In Section 4, we lay out our results, and we summarize the results of robustness checks. In Section 5 we conclude.

\section{The Data and Evidence of Structural Breaks}

The time series we use in our empirical analysis are from Thomson Financial Datastream. When we describe a time series for the first time, we give the Datastream codes in parentheses to facilitate the replication of our results. The yields on BAA and AAA corporate bond portfolios are the only time series that are not from Datastream, but from the FRED database maintained by the 
Federal Reserve Bank of St. Louis. We use the difference between the yields on BAA and AAA corporate bond portfolios to compute the default spread. We use monthly U.S. data that cover the period 1973-2006, where the availability of data governed the selection of the sample period.

\subsection{The Default Spread as an Indicator of Economic and Financial Crises}

The BAA-AAA spread reflects credit market conditions for well-established, highly rated firms, and is strongly indicative of fundamental factors affecting default risk premia (Duca 1999). This spread can, thus, be viewed as a broad-based indicator of the credit quality and the degree of distress in financial markets (White 2000, Adrian and Fleming 2005). The time profile of the default spread is displayed in Figure 1.

\section{- Insert Figure 1 about here. -}

The figure reveals substantial time variation in the size of the spread which can be related to distinct periods of distress in financial markets. Starting from a level of around 80 basis points in 1973 and following the onset of the first oil price shock and the concomitant U.S. recession of 1974-75, the default spread jumps above 200 basis points in 1975, but reverts back to the earlier level within the second half of the 1970s. Beginning in 1980, the spread starts to rise once again to levels above 200 basis points in the wake of the second oil price shock. Unlike in the previous episode, the spread remains at an elevated level throughout most of the 1980s. During that time period, the United States experienced a prolonged bout of distress in financial markets. In 1980, the Federal Reserve under the aegis of Chairman Paul Volcker began tightening the money supply in an attempt to defeat rising inflation, and the U.S. economy experienced the severe 1982 recession. The Latin American debt crisis, originating with the Mexican debt default of August 1982, forced U.S. banks to reschedule debt and to reduce additional lending. Only by forcing developing countries to keep up their interest payments, a major banking collapse was averted. However, the difficulties in U.S. financial markets did not abate but were even further aggravated by the Savings and Loan debacle which became the nation's largest-ever financial scandal. 
Triggered by the bursting of the U.S. real-estate bubble in 1986, the crisis affected commercial banks, savings banks, and savings and loan associations (S\&Ls). In its wake, some 1500 commercial and savings banks and 1200 savings and loan associations failed. In addition, an even larger number of institutions were in precarious financial condition at some time during that period (Kaufman 1994).

After reverting back to roughly its starting level in 1990, the default spread again rises above 100 basis points in 1991. The renewed upsurge of the default premium in 1991 can be associated with the "credit crunch" of 1990-91. The "credit crunch" episode was a period of excessive corporate leverage and bank capitalization problems, forcing banks to substantially cut back on lending (Bernanke and Lown 1991, Bernanke and Gertler 1995: 41). After 1991, the spread begins a secular decline throughout the 1990s with the exception of a brief upward surge around 1998 and 1999, which can be associated with the Asian financial crisis and the problems surrounding LTCM. Following the bursting of the internet bubble, the 9/11 terror attacks and the recession of 2001 , the spread returns to levels of around 150 basis points in 2002 , before falling back to roughly its starting level of 80 basis points in 2004 .

\subsection{Macroeconomic Predictor Variables of Stock Returns}

We use the default spread to study structural breaks and regime changes in the links between stock returns and a number of macroeconomic predictor variables. In order to calculate excess stock returns, we compute the returns on the S\&P 100 market price index (S\&P100Z(PI)), add dividends, and subtract a three-months Treasury bill rate (USI60C..) as our measure of the shortterm interest rate. We use end-of-month data. The list of macroeconomic and financial predictor variables we consider as potential predictors of stock returns comprises six variables that have been used in numerous empirical studies of stock return predictability (Shiller 1984, Chen et al. 1986, Rapach et. al 2005, among many others). These are the dividend yield (DIV_YIELD; S\&P100Z(DY)); the term spread (TSP), defined as the difference between a long-term government 
bond yield (USI61...) and the short-term interest rate; the inflation rate (INF), defined as the change in the natural logarithm of the consumer price index (USI64...F); the change in the natural logarithm of industrial production (DIPA; USI66..IG); the change in the natural logarithm of the narrowly defined money stock (DM1; USOMA033G); and the default spread (DEFSPREAD). In order to minimize the effects of data revisions on our results, we use the twelve-month moving averages of DIPA, INF, and DM1, and we account for a publication lag of one month.

\subsection{Linear Forecasting Regressions and Structural Breaks}

The informational content of the macroeconomic predictor variables for one-month-ahead stock returns can be analyzed by estimating the following linear forecasting model using the ordinary least squares technique:

$r_{t+1}=\beta^{\prime} x_{t}+\varepsilon_{t+1}, \quad t=1,2, \ldots, T-1$,

where $r_{t+1}$ denotes one-month-ahead stock returns, $\beta$ denotes the vector of coefficients to be estimated, $x_{t}$ denotes the vector of explanatory variables, $\varepsilon_{t+1}$ denotes a stochastic disturbance term, and $T$ denotes the sample size. The matrix of explanatory variables contains a constant and our six macroeconomic predictor variables.

\section{- Insert Table 1 about here. -}

Panel A of Table 1 summarizes the estimation results for the linear forecasting model. The estimation results show that the coefficients of the dividend yield (DIVYIELD), the inflation rate (INF), and money supply (DM1) have explanatory power for one-month-ahead stock returns. The adjusted coefficient of determination, however, is relatively small, suggesting that it is difficult to forecast stock returns. The interpretation of the estimation results, however, should not be stretched too far because the linear forecasting model does not account for potential structural breaks in the links between stock returns and the macroeconomic predictor variables. Panel B of Table 1 reports results of tests for structural breaks. The test results provide evidence of structural 
breaks with regard to the informational content of the constant, the dividend yield, industrial production, and money supply for stock returns. The estimated respective months of the structural breaks are 1990/9, 1990/9, 1988/10, and 1985/8. This evidence of a structural break in the forecasting power of the dividend yield is in accordance with results for U.S. stock returns reported by Rapach and Wohar (2006) and Paye and Timmermann (forthcoming).

It is interesting to note that the results of the tests for structural breaks harmonize with our identification of economic and financial crises based on the default spread. For example, at the end of the 1980s, the default spread significantly decreased and our identification suggests that the U.S. economy switched from a crisis regime to a no-crisis regime. The significant decrease in the default spread suggests that accounting for economic and financial crises should be relevant for the specification of the forecasting regression given in Equation (1). A simple way of accounting for structural breaks and regime changes triggered by economic and financial crises is to use an indicator function that identifies such crises. Based on the dynamics of the default spread shown in Figure 1, we define an indicator function, $I_{t}$, that assumes the value one whenever the default spread exceeds 100 basis points, and zero otherwise. We choose 100 basis points to separate the crisis and no-crisis regimes because this value lies in between the mean (108 basis points) and the median (95 basis points) of the default spread. Equipped with this indicator function, we estimate the following forecasting equation:

$r_{t+1}=\beta_{1}{ }^{\prime} x_{t}\left(1-I_{t}\right)+\beta_{2}{ }^{\prime} x_{t} I_{t}+\varepsilon_{t+1}$.

Panel $\mathrm{C}$ of Table 1 summarizes the estimation results. Obviously, the significance and magnitude of the coefficients of the dividend yield, industrial production, the inflation rate, and money supply differ between the crisis and the no-crisis regimes. In fact, the results suggest that macroeconomic variables ("fundamentals") played an important role for forecasting stock returns in the no-crisis regime, and that other, possibly non-fundamental factors were instrumental in the crisis regime. Thus, though the forecasting equation given in Equation (2) could be refined in many ways, the estimation results suggest that taking into account structural breaks and regime changes triggered 
by economic and financial crises should improve the performance of forecasting regressions that link stock returns to macroeconomic variables.

Our analysis of the linear forecasting model extended to accommodate economic and financial crises rests on the assumption that the somewhat arbitrary value of the default spread of 100 basis points is a useful indicator for disentangling the crisis regime from the no-crisis regime. Visual inspection of Figure 1 indicates that using 100 basis points may be a good choice as a threshold to disentangle regimes. In order to quantitatively substantiate the choice of the threshold variable, we estimated, in a first step, the forecasting model given in Equation (2) for various values of the threshold, $d$, using the conditional linear least squares technique as described in Hansen (1997a). In a second step, we store for every estimated model the estimated regression error, $\sigma^{2}(d)=T^{-1} \sum_{t=1}^{T} \hat{\varepsilon}_{t+1}$, where $\hat{\varepsilon}_{t+1}$ denotes the estimated disturbance term. In a third step, we follow Hansen (1997a) and compute the test statistic $L R(d)=T\left(\sigma^{2}(d)-\sigma^{2}\left(d^{*}\right)\right) / \sigma^{2}\left(d^{*}\right)$, where

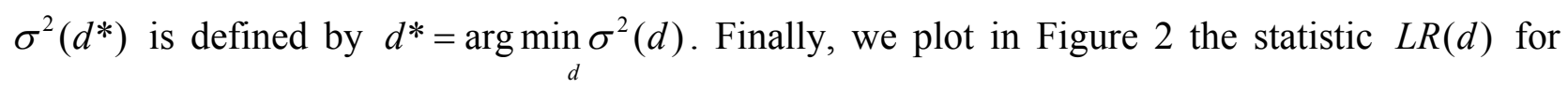
various values of the threshold, $d$. The statistic, $\operatorname{LR}(d)$, assumes the value zero when $d=d^{*}$, i.e., the threshold is equal to the optimal threshold that minimizes the regression error. Figure 2 shows that the optimal threshold, $d^{*}$, is estimated with great precision, because the statistic, $L R(d)$, rapidly increases as $d \neq d^{*}$. The optimal threshold is reached when the default spread assumes a value of 85 basis points. The confidence interval for the threshold, based on critical values reported in Hansen (1997a, Table 1), covers the interval [82, 93]. The estimated optimal threshold is thus close to the value of 100 basis points. In the analysis to follow, we will identify the crisis regime and the no-crisis regime based on a threshold of 100 basis points, a lower threshold of 85 basis points, and an upper threshold of 115 basis points. This is a useful check for the robustness of our empirical results, albeit one should always keep in mind that an investor, in real time, could not have estimated the forecasting model given in Equation (2) because our estimation of the threshold for the default spread is based on full-sample information. 


\section{The Recursive Modeling Approach}

We now describe the recursive modeling approach in three steps. First, we describe how the approach can be used to recursively forecast stock returns in real time. Second, we describe how the approach can be used to assess the performance of simple trading rules. Third, we describe how the real-time forecasts of stock returns implied by the approach can be used to test for market timing.

\subsection{Recursive Forecasting of Stock Returns}

We consider an investor who uses the macroeconomic predictor variables described in Section 2 as candidates for forecasting stock returns. The investor must find out how to combine in an optimal way the macroeconomic predictor variables to future one-month-ahead stock returns. Hence, the investor must reach a decision under uncertainty about the optimal forecasting model. The investor reaches a decision by applying a recursive modeling approach (Pesaran and Timmermann 1995). With $K$ potential macroeconomic predictor variables in hand, the investor searches, in every month, over all possible $2^{K}$ permutations of forecasting models to identify the optimal forecasting model. As time progresses, the investor recursively restarts this search. In line with the forecasting model given in Equation (1), the investor examines forecasting models of the following format:

$r_{t+1}=\beta_{i}{ }^{\prime} x_{t, i}+\varepsilon_{t+1, i}$,

where $i=1,2, \ldots, 2^{K}$ denotes a model index and $x_{t, i}$ denotes the macroeconomic predictor variables under model $i$. We assume that the investor uses five years of monthly data (1973/1-1977/12) as a training period to start the recursive forecasting of stock returns.

Given the large number of forecasting models being estimated in every month (in total we estimated more than seven million models), the investor needs a model-selection criterion to identify the optimal forecasting model. We consider four model-selection criteria: Adjusted Coefficient of Determination (ACD), the Akaike Information Criterion (AIC), the Bayesian 
Information Criterion (BIC), and a Direction-of-Change Criterion (DCC). The definition of the ACD model-selection criterion is given by

$$
A C D_{t, i}=1-\frac{T_{t}-1}{T_{t}-k_{t, i}}\left(1-\frac{r_{t+1}^{\prime} r_{t+1}-e_{t, i}^{\prime} e_{t, i}}{r^{\prime}{ }_{t+1} r_{t+1}}\right),
$$

where $r_{t+1}$, in Equation (4), denotes the vector of returns and $e_{t, i}$ denotes the vector of the estimated residuals under model $i$ in month $t, T_{t}$ denotes the number of observations available in month $t$, and $k_{t, i}$ denotes the number of regressors considered under model $i$ in month $t$. In Equation (4), the variables are measured in deviation from mean. The optimal forecasting model is the one that maximizes the ACD model-selection criterion. The AIC model-selection criterion (Akaike 1973) and the BIC model-selection criterion (Schwarz 1978) are defined as

$$
\begin{aligned}
& A I C_{t, i}=\ln \frac{e_{t, i}{ }^{\prime} e_{t, i}}{T_{t}}+\frac{2 k_{t, i}}{T_{t}}, \\
& B I C_{t, i}=\ln \frac{e_{t, i}{ }^{\prime} e_{t, i}}{T_{t}}+\frac{k_{t, i}}{T_{t}} \ln T_{t} .
\end{aligned}
$$

The optimal forecasting models minimize the AIC and BIC model-selection criteria. Finally, for the implementation of the DCC model-selection criterion, the number of correct in-sample forecasts of the sign of one-month-ahead stock returns is counted for every forecasting model and the following formula is being computed

$$
D C C_{t, i}=\frac{1}{T} \sum_{t=1}^{T}\left[I\left(r_{t}\right) I\left(\hat{r}_{t}\right)+\left(1-I\left(r_{t}\right)\right)\left(1-I\left(\hat{r}_{t}\right)\right)\right]
$$

where $r_{t}$ denotes the actual stock returns in month $t, \hat{r}_{t}$ is the forecast of stock returns implied by model $i$ in month $t$, and $I(a)$ denotes an indicator function that assumes the value one when $a>0$, and zero otherwise. The optimal forecasting model is the one that maximizes the DCC model-selection criterion. 


\subsection{The Performance of Simple Trading Rules}

Given the four model-selection criteria, the recursive modeling approach implies four sequences of optimal forecasting models, and four sequences of one-month-ahead forecasts of stock returns. An investor can use the forecasts of stock returns to set up four simple trading rules. Every trading rule requires that an investor invests in stocks if the forecasts of stock returns are positive, and otherwise invests in bonds. In order to study the performance of the four simple trading rules, we introduce some notation. Our notation follows Pesaran and Timmermann (1995).

An investor's financial wealth at the end of month $t$ is given by $W_{t}$, the price of stocks at the end of month $t$ is given by $P_{t}$, and the dividends paid during month $t$ are given by $D_{t}$. The number of stocks held by an investor at the end of month $t$ is given by $N_{t}$, and an investor's position in bonds is given by $B_{t}$. Trading in stocks and bonds involves transaction costs that are (i) constant through time, (ii) the same for buying and selling stocks and bonds, and (iii) proportional to the value of a trade. The respective trading costs for trading in stocks and bonds are given by $c_{1}$ and $c_{2}$. There is no possibility of short selling. In addition, an investor does not use leverage when making an investment decision. It follows that an investor buys in month $t$ a number of stocks $N_{t}=\left(1-c_{1}\right) W_{t} / P_{t}$ if $\hat{r}_{t+1}>0$, and a number of bonds $B_{t}=\left(1-c_{2}\right) W_{t}$ if $\hat{r}_{t+1}<0$. Finally, for tracking the sequences of investments an investor makes as time progresses, four different cases have to be considered:

- Case 1: The investor invests in stocks in month $t+1$, and reinvests cash dividends in month $t+2$. In this case, we have $\hat{r}_{t+1}>0$ and $\hat{r}_{t+2}>0, N_{t+1}=N_{t}+N_{t} D_{t}\left(1-c_{1}\right) / P_{t+1}$, and $B_{t+1}=0$.

- Case 2: The investor invests in stocks in month $t+1$, but buys bonds in month $t+2$. In this case, we have $\hat{r}_{t+1}>0$ and $\hat{r}_{t+2}<0, N_{t+1}=0$, and $B_{t+1}=\left(1-c_{2}\right)\left[\left(1-c_{1}\right) N_{t} P_{t+1}+N_{t} D_{t+1}\right]$.

- Case 3: The investor invests in bonds in month $t+1$, but buys stocks in month $t+2$. In this case, we have $\hat{r}_{t+1}<0$ and $\hat{r}_{t+2}>0, N_{t+1}=\left(1-c_{1}\right) B_{t}\left(1+R_{t}\right) / P_{t+1}$, and $B_{t+1}=0$. 
- Case 4: The investor invests in bonds in month $t+1$, and continues to invest in bonds in month $t+2$. In this case, we have $\hat{r}_{t+1}<0$ and $\hat{r}_{t+2}<0, N_{t+1}=0$, and $B_{t+1}=\left(1-c_{2}\right) B_{t}\left(1+R_{t}\right)$.

The dynamics of an investor's financial wealth can be traced over time using the budget constraint $W_{t+2}=N_{t+1}\left(P_{t+2}+D_{t+2}\right)+B_{t+1}\left(1+R_{t+1}\right)$, where $R_{t}$ denotes the risk free interest rate on bonds.

The performance of the four simple trading rules can be compared in terms of Sharpe's ratio (Sharpe 1966). Sharpe's ratio is defined as $S R_{j}=\bar{r}_{j} / S D_{j}$, where $S R_{j}$ denotes Sharpe's ratio under trading rule $j, \bar{r}_{j}$ denotes excess returns under trading rule $j$, and $S D_{j}$ denotes the standard deviation of excess returns under trading rule $j$.

\subsection{Market Timing}

We use the nonparametric test developed by Pesaran and Timmermann (1992) to test for market timing. Their test can be used to study the informational content of the forecasts of stock returns, $\hat{r}_{t+1}$, with regard to the sign of one-month-ahead realizations of stock returns, $r_{t+1}$. For conducting the test, one computes the probabilities $P_{1}=P\left(\hat{r}_{t+1}>0\right), P_{2}=P\left(r_{t+1}>0\right)$ and $P=T^{-1} \sum_{t=1}^{T} Z_{t}$, where $Z_{t}=1$ if $\hat{r}_{t+1} \times r_{t+1}>0$, and zero otherwise. Using the definition $P^{*}=P_{1} \times P_{2}+\left(1-P_{1}\right) \times\left(1-P_{2}\right)$, the test is computed as

$P T=\frac{P-P^{*}}{\sqrt{\operatorname{VAR}(P)-\operatorname{VAR}\left(P^{*}\right)}}$,

where $V A R$ denotes the variance operator. The test has an asymptotic standardized normal distribution. The null hypothesis is that there is no information in the forecasts of stock returns over the sign of subsequent realizations of stock returns.

\section{Results}

Table 2 summarizes how often the macroeconomic predictor variables are included in the optimal forecasting models under the four model-selection criteria $\mathrm{ACD}, \mathrm{AIC}, \mathrm{BIC}$, and DCC, when the 
threshold for the default spread that divides the sample into a crisis regime and a no-crisis regime assumes the value of 100 basis points. The results for a lower threshold of 85 points and for a higher threshold of 115 basis points are similar and are not reported for the sake of brevity. The proportion of observations in the crisis regime under a threshold of $85(100,115)$ basis points is 57 $(36,30)$ percent. Variables indexed by the suffix 1 apply in the crisis regime, and variables with a suffix 2 apply in the no-crisis regime. Table 2 shows that the dividend yield and inflation are primarily included in the optimal forecasting models when the U.S. economy was in the no-crisis regime (Regime 2). In contrast, the default spread is primarily included in the optimal forecasting model in the crisis regime (Regime 1). Thus, the inclusion of variables indicates that the informational contents of the macroeconomic predictor variables for forecasting stock returns differs across the crisis regime and the no-crisis regime.

\section{- Insert Table 2 about here. -}

Table 3 summarizes the results with regard to Sharpe's ratio. We report results for a benchmark model that does not account for economic and financial crises, and for three models that account for these crises. The three models feature crisis thresholds of 85,100 , and 115 basis points for the default spread. We also report results for zero, medium-sized, and high transaction costs. Following Pesaran and Timmermann (1995), we assume medium-sized (high) transaction costs of 0.5 and 0.1 of a percent ( 0.1 of a percent and 1 percent) for stocks and bonds, respectively. A comparison of the models that feature crisis thresholds with the benchmark model reveals that the Sharpe's ratios are in general higher if an investor accounts for economic and financial crises when basing simple trading rules on out-of-sample forecasts of stock returns. For the model featuring a crisis threshold of 115 basis points, the higher Sharpe's ratios reflect a lower standard deviation of excess returns than under the benchmark model. For the models featuring crisis thresholds of 85 and 100 basis points, the higher Sharpe's ratios also reflect higher mean excess returns.

\section{- Insert Table 3 about here. -}

Panel A of Table 4 summarizes tests of market timing for the benchmark model and for the models that feature crisis thresholds of 85,100 , and 115 basis points, respectively. In addition, we report 
the noise-to-signal ratio. The noise-to-signal ratio, NTS, is defined as the ratio of the proportion of wrong sign forecasts and the proportion of correct sign forecasts. The NTS ratios should be as small as possible. The results show that accounting for economic and financial crises improves an investor's market-timing ability as compared to the benchmark model. For the benchmark model, the tests for market timing are insignificant in the case of all four model-selection criteria. For the model that features a crisis threshold of 85 basis points, the tests for market timing yield significant results under all four model-selection criteria. For the model that features a crisis threshold of 100 basis points, three out of four tests for market timing yield significant results. Finally, for the model that features a crisis threshold of 115 basis points, only one test for market timing is significant. However, for all model-selection criteria, the results of the test for market timing are much better than under the benchmark model. The NTS ratios support these results. The NTS ratios are smaller than one in the case of the models that feature crisis thresholds, but are larger than one under the benchmark model.

Panel B of Table 4 reports the results of the tests for market timing and the NTS ratios for three additional models. The first model is an extension of the benchmark model to account for potential structural breaks and regime shifts induced by economic booms and recessions. Recessions are identified by means of the NBER classification system. The second model accounts for structural breaks and regime shifts by means of a rolling estimation window. In contrast to the models based on the recursive modeling approach, which is based on an expanding estimation window, this model features a constant five-year rolling estimation window. The third model is based on the assumption of a single structural break in 1989/12. Thus, this model does not account for potential regime changes induced by the economic and financial crises of the 1990s. This third model is tailored to capture the result reported by Aiolfi and Favero (2005) that the statistical and economic significance of the predictability of U.S. stock return has declined in the 1990s. For all three models, the tests for market timing yield insignificant results and the NTS ratios are in general larger than one. This shows that an investor would have benefited more from accounting for economic and financial crises when forming out-of-sample forecasts of stock returns than from (i) accounting for recessions or from accounting for structural breaks, (ii) accounting for regime shifts 
by means of a rolling estimation window, and, (iii) accounting in a mechanical fashion for a potential structural break at the beginning of the 1990s.

\section{Conclusions}

We argue that the use of publicly available and easily accessible information on economic and financial crises to detect structural breaks in the link between stock returns and macroeconomic predictor variables improves the performance of simple trading rules in real time. Our results suggest that accounting for structural breaks and regime shifts in forecasting regressions caused by economic and financial crises has the potential to increase the out-of-sample predictability of stock returns, the performance of simple trading rules, and the market-timing ability of an investor trading in the U.S. stock market.

While we have reported some evidence of a systematic real-time link between economic and financial crises and forecasting regressions of stock returns, a lot of work still needs to be done. Given the mounting empirical evidence of structural breaks and regime shifts in forecasting regressions in economics and finance, it would be important to explore in future research whether results similar to our results can be established for other countries than the U.S. Moreover, because economic and financial crises in emerging market economies tend to be more frequent and very often also much larger than in mature industrialized countries, it would be interesting to explore the implications of our results for forecasting stock returns in emerging market economies. Furthermore, a natural question that could be explored in future research is whether the nature of a crisis matters for forecasting stock returns. For example, one could ask whether banking crises have the same effects on forecasting regressions for stock returns as currency crises. This question could also be used to motivate the development of indicators of economic and financial crises other than the default spread. For example, in the currency-crises literature a number of sophisticated early-warning systems for currency crises have been developed. It would be interesting to analyze whether such early-warning systems can provide guidance for an investor who seeks to compute out-of-sample forecasts of stock returns in real time. 


\section{References}

Adrian, T., and M.J. Fleming, 2005. What financing data reveal about dealer leverage. Federal Reserve Bank of New York Current Issues 11, 1-7.

Aiolfi, M., and C.A. Favero, 2005. Model uncertainty, thick modeling and the predictability of stock returns. Journal of Forecasting 24, 233-254.

Akaike, H., 1973. Information theory and an extension of the maximum likelihood principle. In: B. Petrov, and F. Csake (Eds.), Second International Symposium on Information Theory. Budapest: Akademia Kiado.

Andrews, D.W.K., 1993. Tests for parameter instability and structural change with unknown change point. Econometrica 61, 821-856.

Andrews, D.W.K., and W. Ploberger, 1994. Optimal tests when a nuisance parameter is present only under the alternative. Econometrica 62, 1383-1414.

Ang, A., and G. Bekaert, 2002. International asset allocation with regime shifts. Review of Financial Studies 15, 1137-1187.

Bai, J., and P. Perron, 1998. Estimating and testing linear models with multiple structural changes. Econometrica 66, 47-78.

Bernanke, B.S., and M. Gertler, 1995. Inside the black box: the credit channel of monetary policy transmission. Journal of Economic Perspectives 9, 27-48.

Bernanke, B.S., and C.S. Lown, 1991. The credit crunch. Brookings Papers on Economic Activity 2, 204-239.

Chen, N.F., R. Roll, and S.A. Ross, 1986. Economic forces and the stock market. Journal of Business 59, 383-403.

Cooper, M., H. Gulen, and M. Vassalou, 2001. Investing in size and book-to-market portfolios using information about the macroeconomy: Some new trading strategies. Unpublished Manuscript, Columbia University.

Das, S.R., and R. Uppal, 2004. Systemic risk and international portfolio choice. Journal of Finance $59,2809-2834$.

De Bondt, G., 2005. Does the credit risk premium lead the stock market? Applied Financial Economics Letters 1, 263-268.

Duca, J., 1999. What credit market indicators tell us. Federal Reserve Bank of Dallas Economic and Financial Review, 3rd Quarter, 2-13.

Elton, E.J., M.J. Gruber, D. Agarwal, and C. Mann, 2001. Explaining the rate spread on corporate bonds. Journal of Finance 56, 247-277.

Fama, E., and K. French, 1989. Business conditions and expected returns on stocks and bonds. Journal of Financial Economics 25, 23-49. 
Hansen, B.E., 1997a. Inference in TAR models. Studies in Nonlinear Dynamics and Econometrics $2,1-14$.

Hansen, B.E., 1997b. Approximate asymptotic p-values for structural change tests. Journal of Business and Economic Statistic 15, 60-67.

Kaufman, G.G., 1994. The U.S. banking debacle of the 1980s: an overview and lessons, Center for Financial and Policy Studies Working Paper 94-6, Loyola University of Chicago.

Kole, E., K. Koedijk, and M. Verbeek, 2006. Portfolio implications of systemic risk. Journal of Banking and Finance 30, 2347-2369.

Lui, J., F.A. Longstaff, and J. Pan, 2003. Dynamic asset allocation with event risk. Journal of Finance 58, 231-259.

Paye, B.S., and A. Timmermann, 2006. Instability of return prediction models. Journal of Empirical Finance 13, 274-315.

Perez-Quiros, G., and A. Timmermann, 2000. Firm size and cyclical variations in stock returns. Journal of Finance 55, 1229-1262.

Pesaran, M.H., and A. Timmermann, 1992. A simple nonparametric test of predictive performance. Journal of Business and Economic Statistics 10, 461-465.

Pesaran, M.H., and A. Timmermann, 1995. The robustness and economic significance of predictability of stock returns. Journal of Finance 50, 1201-1228.

Pesaran, M.H., and A. Timmermann, 2000. A recursive modelling approach to predicting UK stock returns. Economic Journal 110, 159-191.

Pesaran, M.H., and A. Timmermann, 2002. Market timing and return prediction under model instability. Journal of Empirical Finance 9, 495-510

Rapach, D.E., and M.E. Wohar, 2006. Structural breaks and predictive regressions models of aggregate U.S. stock returns. Journal of Financial Econometrics 4, 238-274.

Rapach, D.E., M.E. Wohar, and J. Rangvid, 2005. Macro variables and international stock return predictability. International Journal of Forecasting 21, 137-166.

Schwarz G., 1978. Estimating the dimension of a model. Annals of Statistics 6, 416-464

Sharpe, W.F., 1966. Mutual fund performance. Journal of Business 39, 119-138.

Shiller, R.J., 1984. Stock prices and social dynamics. Brookings Papers on Economic Activity 2, 457-498.

Timmermann, A., 2001. Structural breaks, incomplete information, and stock prices. Journal of Business and Economics Statistics 19, 299-314.

White, W.R., 2000. What have we learned from recent financial crises and policy responses? In: J.R. Bisignano, W.C. Hunter, and G.G. Kaufman (Eds.), Global financial crises: Lessons from Recent Events, 177-200, Springer, Berlin.

Whitelaw, R.F., 1997. Time-varying Sharpe ratios and market timing. Unpublished manuscript, New York University. 


\section{Tables and Figures}

Figure 1 - The default spread, 1973-2006

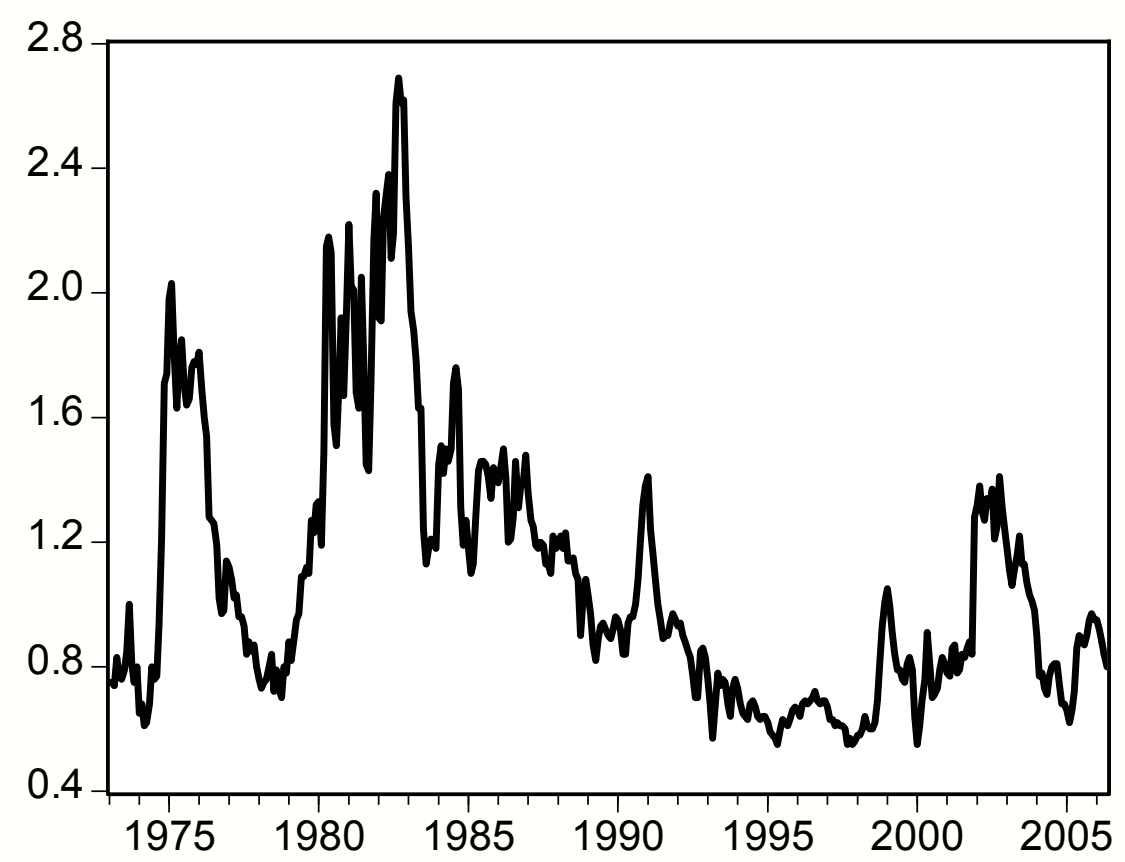

Note: The default spread is defined as the difference between the yields on BAA and AAA rated corporate bond portfolios as described in Section 2.1. 
Figure 2 - The estimated threshold of the default spread

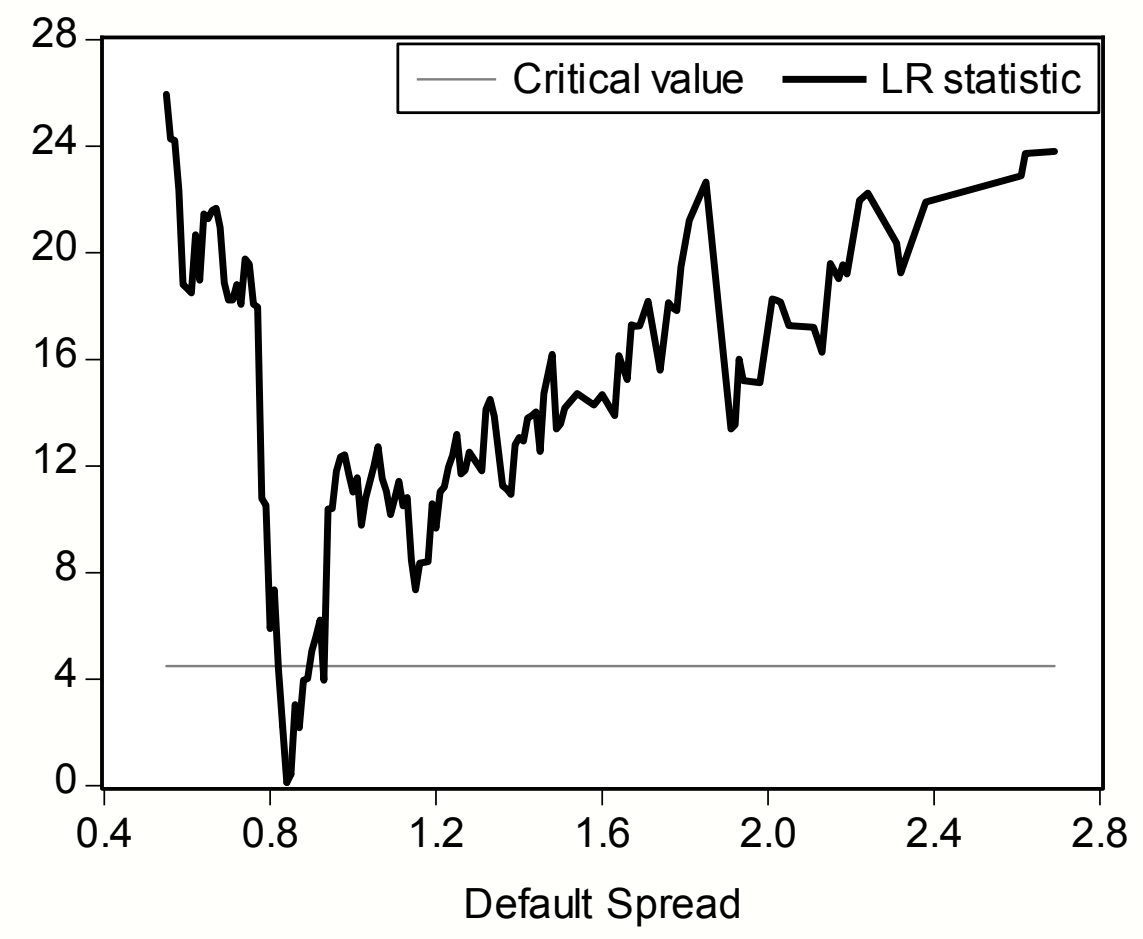

Note: This figure shows the LR statistic as a function of the threshold for the default spread. The LR statistic is explained in Section 2.3. The critical value for an 80 percent level of confidence is taken from Hansen (1997a, Table 1). 
Table 1 - The linear forecasting model, 1973-2006

Panel A: Estimation results without accounting for economic and financial crises

\begin{tabular}{l|ccc}
\hline \hline & Coefficient & Std. error & t-statistic \\
\hline Constant & 0.002 & 0.009 & 0.265 \\
DIVYIELD & 0.009 & 0.003 & $2.697^{* * *}$ \\
DIPA & -0.009 & 0.008 & -1.131 \\
INF & -0.048 & 0.019 & $-2.502^{* *}$ \\
TSP & 0.001 & 0.002 & 0.266 \\
DEFSPREAD & 0.006 & 0.008 & 0.660 \\
DM1 & -0.024 & 0.008 & $-3.063^{* * *}$ \\
\hline \multicolumn{2}{l}{ Durbin-Watson statistic } & & 2.031 \\
Adjusted R & & & 0.031 \\
\hline \hline
\end{tabular}

Panel B: Tests for structural breaks

\begin{tabular}{l|cc|cc}
\hline \hline & \multicolumn{2}{|c|}{ Andrews-Quandt test } & \multicolumn{2}{c}{$\begin{array}{c}\text { Andrews-Ploberger } \\
\text { test }\end{array}$} \\
& test & p-value & test & p-value \\
\hline Constant & 6.869 & 0.110 & 1.376 & 0.116 \\
DIVYIELD & 10.010 & $0.026^{* *}$ & 1.698 & $0.077^{*}$ \\
DIPA & 13.427 & $0.005^{* * *}$ & 4.758 & $0.001^{* * *}$ \\
INF & 6.562 & 0.126 & 0.834 & 0.253 \\
TSP & 2.644 & 0.631 & 0.434 & 0.497 \\
DEFSPREAD & 5.331 & 0.215 & 0.792 & 0.270 \\
DM1 & 8.554 & $0.051^{*}$ & 1.239 & 0.140 \\
\hline \hline
\end{tabular}

Panel C: Estimation results with accounting for economic and financial crises

\begin{tabular}{l|ccc|c|ccc}
\hline \hline & \multicolumn{3}{|c|}{ Crisis regime } & & \multicolumn{3}{c}{ No-crisis regime } \\
& Coefficient & Std. error & t-statistic & & Coefficient & Std. error & t-statistic \\
\hline Constant & -0.011 & 0.021 & -0.528 & Constant & -0.008 & 0.027 & -0.307 \\
DIVYIELD & 0.007 & 0.005 & 1.379 & DIVYIELD & 0.017 & 0.005 & $3.100^{* * *}$ \\
DIPA & -0.014 & 0.011 & -1.310 & DIPA & 0.013 & 0.015 & 0.894 \\
INF & -0.029 & 0.023 & -1.249 & INF & -0.117 & 0.040 & $-2.902^{* * *}$ \\
TSP & 0.000 & 0.003 & 0.018 & TSP & 0.001 & 0.004 & 0.321 \\
DEFSPREAD & 0.010 & 0.014 & 0.718 & DEFSPREAD & 0.015 & 0.030 & 0.507 \\
DM1 & -0.011 & 0.016 & -0.698 & DM1 & -0.027 & 0.012 & $-2.303^{* *}$ \\
\hline Durbin-Watson statistic & \multicolumn{3}{l}{} \\
Adjusted R &
\end{tabular}

Note: The tests for structural breaks in the forecasting regression of one-month-ahead stock returns on macroeconomic predictor variables are described in detail in Andrews (1993), Andrews and Ploberger (1994), and Hansen (1997b).*** (**,*) denote significance at the one (five, ten) percent level. The sample period is 1973/1-2006/6. For definitions of variables, see Section 2.2. 
Table 2 - Inclusion of variables in optimal forecasting models in percent, 1978-2006

\begin{tabular}{l|cccc}
\hline \hline Variables & ACD & AIC & BIC & DCC \\
\hline DIVYIELD_1 & 11.76 & 0.29 & 0.00 & 69.71 \\
DIVYIELD_2 & 99.41 & 99.41 & 89.71 & 95.00 \\
DIPA_1 & 52.06 & 33.82 & 0.00 & 72.35 \\
DIPA_2 & 10.00 & 2.35 & 0.00 & 77.65 \\
INF_1 & 62.94 & 9.12 & 0.59 & 30.88 \\
INF_2 & 99.12 & 97.35 & 56.47 & 70.88 \\
TSP_1 & 9.71 & 1.76 & 0.00 & 34.41 \\
TSP_2 & 9.71 & 0.00 & 0.00 & 38.24 \\
DEFSPREAD_1 & 90.88 & 74.12 & 65.00 & 80.59 \\
DEFSPREAD_2 & 16.76 & 3.53 & 0.00 & 61.18 \\
DM1_1 & 31.47 & 4.12 & 0.00 & 45.59 \\
DM1_2 & 39.71 & 36.76 & 32.65 & 18.82 \\
\hline \hline
\end{tabular}

Note: ACD denotes the Adjusted Coefficient of Determination, AIC denotes the Akaike Information Criterion, BIC denotes the Bayesian Information Criterion, and DCC denotes the Direction-of-Change Criterion. The threshold value of the default spread used to identify a crisis regime and a no-crisis regime is 100 basis points. The variable DIVYIELD_1 denotes the dividend yield in the crisis regime (Regime 1), and the variable DIVYIELD_2 denotes the dividend yield in the no-crisis regime (Regime 2). The names of the other variables can be interpreted in an analogous way. For definitions of variables, see Section 2.2. The investor uses five years of monthly data (1973/1-1977/12) as a training period to start the recursive forecasting of stock returns. 
Table 3 - Sharpe's ratio for simple trading rules, 1978-2006

\begin{tabular}{l|c|c|c|c}
\hline \hline \multicolumn{1}{c}{$\begin{array}{c}\text { Benchmark } \\
\text { model }\end{array}$} & $\begin{array}{c}\text { Model with a } \\
\text { threshold of 85 } \\
\text { basis points }\end{array}$ & $\begin{array}{c}\text { Model with a } \\
\text { threshold of 100 } \\
\text { basis points }\end{array}$ & $\begin{array}{c}\text { Model with a } \\
\text { threshold of 115 } \\
\text { basis points }\end{array}$ \\
\hline \multicolumn{5}{c}{ Zero transaction costs } \\
\hline ACD & 0.2305 & 0.2642 & 0.2376 & 0.2797 \\
AIC & 0.2189 & 0.2539 & 0.2344 & 0.2561 \\
BIC & 0.1974 & 0.2553 & 0.2185 & 0.2547 \\
DCC & 0.1981 & 0.2657 & 0.2571 & 0.2224 \\
\hline \multicolumn{5}{|c}{ Medium-sized transaction costs } \\
\hline ACD & 0.2178 & 0.2410 & 0.2104 & 0.2536 \\
AIC & 0.2069 & 0.2327 & 0.2096 & 0.2293 \\
BIC & 0.1821 & 0.2391 & 0.1886 & 0.2312 \\
DCC & 0.1763 & 0.2330 & 0.2219 & 0.1834 \\
\hline \multicolumn{5}{|c|}{ High transaction costs } \\
\hline ACD & 0.2077 & 0.2228 & 0.1888 & 0.2349 \\
AIC & 0.1974 & 0.2157 & 0.1899 & 0.2084 \\
BIC & 0.1749 & 0.2258 & 0.1655 & 0.2133 \\
DCC & 0.1596 & 0.2065 & 0.1945 & 0.1510 \\
\hline \hline
\end{tabular}

Note: ACD denotes the Adjusted Coefficient of Determination, AIC denotes the Akaike Information Criterion, BIC denotes the Bayesian Information Criterion, and DCC denotes the Direction of Change Criterion. In every month, the investor selects four optimal forecasting models according to the ACD, AIC, BIC, and DCC model-selection criteria. For switching between stocks and bonds, the investor uses information on the optimal one-month-ahead stockreturn forecasts implied by the optimal forecasting models. When the optimal one-month-ahead stock-return forecasts are positive (negative), the investor only invests in shares (bonds), not in bonds (shares). The investor does not make use of short selling, nor does the investor use leverage when reaching an investment decision. We assume medium-sized (high) transaction costs of 0.5 and 0.1 of a percent ( 0.1 of a percent and 1 percent) for stocks and bonds, respectively. The benchmark model does not account for economic and financial crises. The investor uses five years of monthly data (1973/1-1977/12) as a training period to start the recursive forecasting of stock returns. 
Table 4 - Tests of market timing

Panel A: Results for a benchmark model and models featuring crises thresholds

\begin{tabular}{|c|c|c|c|c|}
\hline & $\mathrm{ACD}$ & $\mathrm{AIC}$ & $\mathrm{BIC}$ & $\mathrm{DCC}$ \\
\hline \multicolumn{5}{|c|}{ Benchmark model } \\
\hline PT & -0.69 & -0.58 & -0.84 & -2.52 \\
\hline NTS & 1.02 & 1.02 & 1.06 & 1.14 \\
\hline \multicolumn{5}{|c|}{ Model with a threshold of 85 basis points } \\
\hline $\mathrm{PT}$ & $2.03 * *$ & $2.00 * *$ & $2.32 * * *$ & $1.76^{* *}$ \\
\hline NTS & 0.89 & 0.89 & 0.90 & 0.89 \\
\hline \multicolumn{5}{|c|}{ Model with a threshold of 100 basis points } \\
\hline PT & $1.40^{*}$ & $1.56^{*}$ & $1.76^{* *}$ & 1.10 \\
\hline NTS & 0.92 & 0.91 & 0.89 & 0.92 \\
\hline \multicolumn{5}{|c|}{ Model with a threshold of 115 basis points } \\
\hline PT & $1.61^{*}$ & 0.82 & 0.01 & 0.58 \\
\hline NTS & 0.90 & 0.95 & 1.00 & 0.96 \\
\hline
\end{tabular}

Panel B: Results for three alternative models

\begin{tabular}{|c|c|c|c|c|}
\hline & $\mathrm{ACD}$ & $\mathrm{AIC}$ & $\mathrm{BIC}$ & $\mathrm{DCC}$ \\
\hline \multicolumn{5}{|c|}{ Model with regimes based on NBER recessions } \\
\hline PT & -0.52 & -1.57 & 0.46 & -1.17 \\
\hline NTS & 1.03 & 1.02 & 1.07 & 1.14 \\
\hline \multicolumn{5}{|c|}{ Benchmark model with a rolling estimation window } \\
\hline PT & 0.28 & -0.25 & -0.80 & 0.94 \\
\hline NTS & 0.98 & 1.02 & 1.05 & 0.94 \\
\hline \multicolumn{5}{|c|}{ Model with a structural break in $1989 / 12$} \\
\hline PT & -1.02 & -1.14 & -1.79 & -0.08 \\
\hline NTS & 1.06 & 1.06 & 1.07 & 1.00 \\
\hline
\end{tabular}

Note: PT denotes the nonparametric tests for market timing developed by Pesaran and Timmermann (1992). The Pesaran-Timmermann test has asymptotically a standard normal distribution. NTS denotes the noise-to-signal ratio, defined as the ratio of the proportion of wrong sign forecasts and the proportion of correct sign forecasts. The benchmark model does not account for economic and financial crises. 